\title{
Hand Hygiene in Healthcare Settings: Clean Hands Save Lives
}

\author{
Farideh Shiva ${ }^{1, *}$ \\ ${ }^{1}$ Pediatric Infections Research Center, Mofid Children's Hospital, Shahid Beheshti University of Medical Sciences, Tehran, IR Iran \\ ${ }^{*}$ Corresponding author: Farideh Shiva, Pediatric Infections Research Center, Shahid Beheshti University of Medical Sciences, Tehran, IR Iran. Tel: +98-2122756583, E-mail: faridehshi- \\ va@gmail.com.
}

Received: January 3, 2014; Accepted: January 10, 2014

Keywords:Hand Hygiene; Delivery of Health Care; Infections

Health care associated infections (HCAI), lead to significant morbidity and mortality in hospitalized patients. It has been estimated that about 1.5 million patients incur HCAI at any time throughout the world. In industrialized countries up to $15 \%$ of patients admitted to the hospitals and up to $37 \%$ of those admitted to the intensive care units (ICUs) may contract HCAI; these figures are much higher in developing countries. The risk of infections associated with various devices and procedures, like central venous lines, mechanical ventilations, and urinary catheters rises sharply in the ICU setting (1).

Repeated studies have recognized health care personnel (HCP) as the prime source for the dissemination of pathogenic microorganisms between different patients, proper implementation of hand hygiene by professionals caring for patients has been shown to decrease the rate of hospital acquired infections (1-3).

The role of hand hygiene in preventing infections has been known since the mid-nineteenth century when Ignaz Semmelweiss, a physician in the General Hospital in Vienna, noticed that maternal mortality in the maternity clinic, where deliveries were performed by physicians, who assisted women in labor after performing autopsies, was much higher than the clinic managed by midwives. He advised all personnel to wash their hands with a chlorinated lime solution before performing deliveries. This intervention resulted in an abrupt fall in maternal mortality from around $16 \%$ to less than $3 \%$ (1). This was the first evidence indicating that cleansing heavily contaminated hands with an antiseptic agent may reduce healthcareassociated transmission of contagious diseases more effectively than hand washing with plain soap and water.

To reduce the risk of transmission of pathogens in health care settings, the world health organization (WHO) has developed the concept of 'five moments' for implementing hand hygiene: before touching the patient, before aseptic procedures, after body fluid exposure, after touching a patient, and after touching patient's surroundings $(1,2,4)$.
Hand hygiene refers to any procedure that leads to cleansing of hands; this includes washing hands with ordinary or antibacterial soap and water or using an antiseptic rub which is usually alcohol-based. Hand washing results in decontamination of obviously soiled hands and removes transient flora on the skin surface, while using the antiseptic hand rub inactivates the transient pathogens as well as the flora resident just under the stratum corneum, but it does not remove dirt from soiled hands $(1,5)$. Transient flora are usually associated with HCAI as health care workers acquire the microorganisms from one patient and transmit these to others (5). Alcohol hand rubs reduce bacterial counts on hands more effectively than washing with soap and water; however, hand rubs are ineffective in eradicating Clostridium difficile, that need hand washing to physically remove the pathogens. Many preparations of alcohol rubs contain emollients to prevent skin drying; as alcohol rubs are flammable, these must be stored away from burning stoves (1). After washing, hands must be thoroughly dried with disposable towels as microorganisms are transferred easily and in large numbers from wet hands (5).

Situations where sterile or disposable gloves are needed have been defined clearly; however it is emphasized that gloves do not replace the need for hand hygiene which must be performed both before gloves are put on and after these are removed. Inappropriate use of gloves results in waste of resources and may actually increase the transmission of infections. Often HCP use gloves for self-protection; they may not change the gloves and/or wash their hands between different tasks requiring hand hygiene (1). Regular monitoring of health care professionals regarding compliance with hand hygiene remains a crucial component of infection control programs. Rates of adherence of HCP to implementation of hand hygiene according to the recommended procedures varying from $5 \%$ to $89 \%$ have been reported by various health organizations globally (5). 
Knowledge and attitudes of HCP about hand hygiene have also been extensively assessed in various studies; majority of HCP possess the necessary knowledge, however their attitudes and practice are influenced by various factors (5-7). Availability and accessibility of ample facilities for hand washing are important prerequisites for optimal implementation of hand hygiene (3). Skin irritation by repeated hand washing, insufficient time because of work overload, lack of continuous surveillance, no accountability and having no role model have also been cited as possible reasons for poor compliance with hand hygiene (6-8).

Various methods for measuring health care worker adherence to hand hygiene practices have been advocated, including direct observation by trained observers or by patients, self-reporting by health workers, consumption of hygiene products like soap, alcohol rub etc. and automated monitoring systems each method has its own advantages and disadvantages. Although there is no ideal method for measurement, but direct observation has been recognized as the gold standard (1). However, if personnel are aware of being observed, they will modify their behavior, (Hawthorne effect) (9). In order to obtain a true measure of hand hygiene compliance, observers should be chosen from individuals who are customarily present in the wards and are trained to observe and document their findings without attracting notice.

Standard observation tools to measure hand hygiene compliance have been devised by the WHO and other organizations; these tools have been tested and validated in various hospitals in different countries $(1,10)$.

In order to reduce the rate of hospital acquired infections, the importance of optimal hand hygiene practices cannot be overemphasized. All possible strategies that would result in improving hand hygiene behavior should be put into action to achieve this goal, including regular training, provision of sufficient facilities such as posters and reminders, repeated surveillances, addressing HCP concerns about skin damage, preventing understaffing to decrease the work load and increase the positive feedback.

\section{Financial Disclosure}

The author had no relevant financial interests or financial conflicts within the past 5 years and for the foreseeable future.

\section{References}

1. World Health Organization.Clean Care is Safer Care Team. The WHO Guidelines on Hand Hygiene in Health Care. 2009. Available from http://whqlibdoc.who.int/publications/2009/9789241597906_ eng.pdf.

2. Clean Care is Safer Care. WHO Five Moments for Hand Hygiene. Available from: www.who.int/gpsc/tools/Five_moments/.

3. Devnani M, Kumar R, Sharma RK, Gupta AK. A survey of handwashing facilities in the outpatient department of a tertiary care teaching hospital in India. J Infect Dev Ctries. 2011;5(2):114-8.

4. Sax H, Allegranzi B, Chraiti MN, Boyce J, Larson E, Pittet D. The World Health Organization hand hygiene observation method. Am J Infect Control. 2009;37(10):827-34.

5. Boyce JM, Pittet D, Healthcare Infection Control Practices Advisory Committee, Hicpac Shea Apic Idsa Hand Hygiene Task Force. Guideline for Hand Hygiene in Health-Care Settings. Recommendations of the Healthcare Infection Control Practices Advisory Committee and the HICPAC/SHEA/APIC/IDSA Hand Hygiene Task Force. Society for Healthcare Epidemiology of America/Association for Professionals in Infection Control/Infectious Diseases Society of America. MMWR Recomm Rep. 2002;51(RR-16):1-45.

6. Pittet D. Improving compliance with hand hygiene in hospitals. Infect Control Hosp Epidemiol. 2000;21(6):381-6.

7. Pessoa-Silva CL, Posfay-Barbe K, Pfister R, Touveneau S, Perneger TV, Pittet D. Attitudes and perceptions toward hand hygiene among healthcare workers caring for critically ill neonates. Infect Control Hosp Epidemiol. 2005;26(3):305-11.

8. Institute for Healthcare Improvement. How-to Guide: Improving Hand Hygiene. A Guide for Improving Practices among Health Care Workers. Available from: http://www.IHI.org.

9. The Joint Commission. Measuring Hand Hygiene Adherence: Overcoming the challenges. 2009. Available from: http://www.jointcommission.org.

10. Fuller C, McAteer J, Slade R, Cookson B, Michie S, Stone S. Shor Summary of Hand Hygiene Observation Tool (HHOT). Feedback In tervention Trial, Royal Free And University College. 2007. Available from: http://www.idrn.org/nosec.php. 